Research Article

\title{
Dietary pattern and obesity among children: descriptive study
}

\section{Viswanatha P. G.*, Ramakrishna Reddy N, Shanmugapriya D, Tejaswi H. J., Subathra V}

Department of Community Medicine, BMCRI, Bengaluru, Karnataka, India

Received: 15 May 2016

Accepted: 20 May 2016

*Correspondence:

Dr. Viswanatha PG,

E-mail: vgowd300@gmail.com

Copyright: (c) the author(s), publisher and licensee Medip Academy. This is an open-access article distributed under the terms of the Creative Commons Attribution Non-Commercial License, which permits unrestricted non-commercial use, distribution, and reproduction in any medium, provided the original work is properly cited.

\section{ABSTRACT}

Background: Obesity has also been seen as the product of gluttony. It is difficult to know what control eating in different human beings, as it involves many learned responses and basic physiological drives for eating and satiety, as well as psychosocial factors.

Methods: The sample size of the study was 1718. After taking consent from the school authorities, a pre-tested semi structured questionnaire was self-administered to the students in the classroom and asked them to enter the relevant data, weight and height of the students were recorded following standard protocol and BMI was found.

Results: The prevalence of overweight and obesity is high among study subjects who eat food from fast food centre $(21.8 \%)$ compared to those who do not eat from fast food centre $(10.7 \%)$ which is statistically significant.

Conclusions: It has been found in this study that sweets, egg, meat, and snacks are highly significant in increasing the prevalence of overweight/obesity.

Keywords: Obesity, Dietary pattern, Children

\section{INTRODUCTION}

The first physiological contact of the child with the environment is in the uterus. The mother's metabolism during pregnancy interacts with the fetus with respect to the development of the metabolic regulatory mechanisms. ${ }^{1}$

After birth, the method of feeding and weaning may theoretically influence the risk of obesity. Feeding practices in turn have been reported to subsequently influence children's food choices. In the development of children's food preferences, family lifestyle and food habits play an important role. Nguyen et al revealed that parents' adiposity and fat intake are in many ways associated with their children's adiposity and fat intake, which suggests that familial similarities in food consumption may partially explain familial patterns of adiposity. ${ }^{2}$ The attitudes and behaviour of parents, peers, siblings and relatives who live with the children also highly affect children's eating habits. Moreover, parents' encouragement to eat promotes fat gain in their children. ${ }^{3}$

Weight gain is the result of an imbalance between energy intake (EI) and total energy expenditure (TEE), but the mechanism of this imbalance remains unclear, and this varies from person to person. Obesity develops due of an excess EI relative to TEE, a reduced TEE relative to EI, or a combination of both. ${ }^{4}$

Obesity has also been seen as the product of gluttony. It is difficult to know what control eating in different human beings, as it involves many learned responses and basic physiological drives for eating and satiety, as well as psychosocial factors.

However, there are number of methods available to measure what people eat. Generally, it is known that all individuals under-report their intake; the obese by more than those of normal weight. ${ }^{5}$ It is beyond the scope of this literature review to produce a comprehensive review 
of methods of measuring dietary intake. However, Willett has critically reviewed a number of methods including food frequency method of measuring food intake including, 24-hour dietary recall and food record methods. ${ }^{6}$ In terms of their advantages and disadvantages for studies of individuals and at a population level, a number of recent studies also have addressed specific issues of comparing the use of different methods, especially the use of short questionnaires for population based surveys. ${ }^{7,8}$

In terms of measuring food, 24-hour recall is one of the most frequently used in population based studies. It has been generally concluded that the food and nutrient intake from a 24 hour recall method does not represent the usual or average intake of an individual. However, it is more reliable for estimating intakes at a group level, where participants under and over estimates of their consumption cancels out and produces a fairly stable estimate of the group's mean consumption. ${ }^{9}$ Many studies investigating the validity of 24 hour recalls have found them to have acceptable levels of validity in most populations. $^{10,11}$ When comparing with other dietary intake methods, the 24 hour recall has been found to have acceptable levels of concurrent validity with weighed food records, the dietary history method, and FFQs. ${ }^{11}$ However, it should be also recognized that 24 hour recall has some limitations. Firstly, as dietary intake varies considerably from day to day, particularly in young people, the 24 hour recall method does not provide an accurate estimate of an individual's usual food and nutrient intake.

To date, the dietary emphasis on the causes of obesity has been on total energy intake and the proportion of macronutrients. Many studies, however, have failed to show a correlation between individual energy intake and adiposity in children and adolescents. Rolland $\mathrm{C}$ et al. revealed that no correlation was found between energy intake and individual corpulence (BMI and skinfold thickness) in a population of French children, but a higher proportion of overweight children was found in lower social classes where energy intake is traditionally higher. $^{12}$ The authors also found that daily energy intake was not higher in obese compared with non-obese French adults, but obesity was more prevalent in social groups where energy intake is higher. ${ }^{13}$ This suggests that socially determined factors, such as a high-energy diet, are conducive to the development of obesity.

\section{METHODS}

A cross sectional study was carried out among high school students to find the body mass index pattern in relation to dietary habits. Students studying in $8^{\text {th }}, 9^{\text {th }}$ and $10^{\text {th }}$ standard were the study subjects. This study was conducted among government, private aided and private unaided schools. These schools were selected by simple random sampling and the required study subjects were selected based on stratified random sampling after finding probability proportionate sampling size.

The sample size of the study was 1718. After taking consent from the school authorities, a pre-tested semi structured questionnaire was self-administered to the students in the classroom and asked them to enter the relevant data, weight and height of the students were recorded following standard protocol and BMI was found. Data was entered in Microsoft excel and analyzed in SPSS.

\section{RESULTS}

$96 \%$ of study subjects are non-vegetarians and only $4 \%$ are vegetarians. The prevalence of overweight/obesity is $18.4 \%$ among non-vegetarians and is $14.7 \%$ among vegetarians. Even though the difference is of $3.7 \%$, it is not statistically significant (Table 1).

Table 1: Relation between food habit and overweight/obesity.

\begin{tabular}{|lllllll|}
\hline Food & \multicolumn{2}{l}{ Overweight/obese } & \multicolumn{2}{l|}{ Others $^{\#}$} & \multicolumn{2}{l|}{ Total* } \\
habit & $\mathbf{N}$ & $\mathbf{\%}$ & $\mathbf{N}$ & $\mathbf{\%}$ & $\mathbf{N}$ & $\mathbf{\%}$ \\
\hline $\begin{array}{l}\text { Non } \\
\text { veg. }\end{array}$ & 304 & 18.4 & 1346 & 81.6 & 1650 & 96.0 \\
\hline Veg. & 10 & 14.7 & 58 & 85.3 & 68 & 4.0 \\
\hline Total & 314 & 18.3 & 1404 & 81.7 & 1718 & 100 \\
\hline
\end{tabular}

*(\%)-column percentage, \#Underweight and Normal weight Chi square value-0.60, df-1, p value-0.43, Odds ratio-1.31 (95\% CI; 0.64-2.76).

Table 2: Relation between eating food/snacks between breakfast-lunch-supper and overweight/obesity.

\begin{tabular}{|c|c|c|c|c|c|c|}
\hline \multirow{2}{*}{$\begin{array}{l}\text { Eating } \\
\text { b/w } \\
\text { BF- } \\
\text { LU- } \\
\text { SU }\end{array}$} & \multicolumn{2}{|c|}{$\begin{array}{l}\text { Overweight } \\
\text { /obese }\end{array}$} & \multicolumn{2}{|c|}{ Others $^{\#}$} & \multicolumn{2}{|c|}{ Total* } \\
\hline & $\mathbf{N}$ & $\%$ & $\mathbf{N}$ & $\%$ & $\mathbf{N}$ & $\%$ \\
\hline Yes & 267 & 18.4 & 1186 & 81.6 & 1453 & 84.6 \\
\hline No & 47 & 17.7 & 218 & 82.3 & 265 & 15.4 \\
\hline Total & 314 & 18.3 & 1404 & 81.7 & 1718 & 100 \\
\hline
\end{tabular}

Table 3: Distribution of study subjects based on eating food from fast food centre.

\begin{tabular}{|lll|}
\hline Eating from fast food/week & Frequency & Percent \\
\hline No & 544 & 31.7 \\
\hline $1-2$ times & 848 & 49.4 \\
\hline 3-4 times & 188 & 10.9 \\
\hline >4 times & 138 & 8.0 \\
\hline Total & 1718 & 100.0 \\
\hline
\end{tabular}


Table 4: Relation between eating food from Fast food centre and overweight/obesity.

\begin{tabular}{|lllllll|}
\hline Fast & \multicolumn{2}{l}{$\begin{array}{l}\text { Overweight } \\
\text { obese }\end{array}$} & \multicolumn{2}{l}{ Others $^{\#}$} & \multicolumn{2}{l|}{ Total $^{*}$} \\
\hline Yes & N & \% & N & \% & N & \% \\
\hline No & 256 & 21.8 & 918 & 78.2 & 1174 & 68.3 \\
\hline Total & 58 & 10.7 & 486 & 89.3 & 544 & 31.7 \\
\hline
\end{tabular}

*(\%) column percentage, \#Underweight and Normal weight, Chi square value- 30.90 , df- $1, \mathrm{p}$ value- 0.00 , odds ratio- 2.33 (95\% CI;1.72-3.917)
Table 5: Relation between frequency of eating food from Fast food centre and overweight/obesity.

\begin{tabular}{|lllllll|}
\hline \multirow{2}{*}{ Fast food } & \multicolumn{2}{l}{$\begin{array}{l}\text { Overweight } \\
\text { /obese }\end{array}$} & \multicolumn{2}{l}{ Others $^{\#}$} & \multicolumn{2}{l|}{ Total* $^{*}$} \\
& $\mathbf{N}$ & $\mathbf{\%}$ & $\mathbf{N}$ & $\mathbf{\%}$ & $\mathbf{N}$ & $\mathbf{\%}$ \\
\hline >2times/week & 133 & 40.8 & 193 & 59.2 & 326 & 27.8 \\
\hline 1-2times/weel & 123 & 14.5 & 725 & 85.5 & 848 & 72.2 \\
\hline Total & 256 & 21.8 & 918 & 78.2 & 1174 & 100 \\
\hline
\end{tabular}

*(\%) column percentage, \#Underweight and Normal weight, Chi square value-95.47, df- $1, \mathrm{p}$ value- 0.00 , odds ratio-4.06 (95\%CI;3.03-5.44)

Table 6: Relation between food frequency and overweight/obesity.

\begin{tabular}{|c|c|c|c|c|c|c|}
\hline Food item & Overweight/obese & Others $^{\#}$ & Total & Odds ratio & $95 \% \mathrm{CI}$ & P-value \\
\hline \multicolumn{4}{|l|}{ Sweets } & \multirow{3}{*}{1.38} & \multirow{3}{*}{$1.02-1.86$} & \multirow{3}{*}{0.02} \\
\hline 1-7 times/week & $244(19.5 \%)$ & $1006(80.5 \%)$ & 1250 & & & \\
\hline$<1$ time/week or never & $70(15 \%)$ & $398(85 \%)$ & 468 & & & \\
\hline \multicolumn{4}{|l|}{ Egg } & \multirow{3}{*}{1.28} & \multirow{3}{*}{$0.99-1.66$} & \multirow{3}{*}{0.04} \\
\hline 1-7 times/week & $188(20 \%)$ & $755(80 \%)$ & 943 & & & \\
\hline$<1$ time/week or never & $126(16.3 \%)$ & $649(83.7 \%)$ & 775 & & & \\
\hline \multicolumn{4}{|l|}{ Meat } & \multirow{3}{*}{1.42} & \multirow{3}{*}{$1.10-1.84$} & \multirow{3}{*}{0.00} \\
\hline 1-7 times/week & $132(21.8 \%)$ & $475(78.2 \%)$ & 607 & & & \\
\hline$<1$ time/week or never & $182(16.4 \%)$ & $929(83.6 \%)$ & 1111 & & & \\
\hline \multicolumn{4}{|l|}{ Milk/curd } & \multirow{3}{*}{1.26} & \multirow{3}{*}{$0.91-1.74$} & \multirow{3}{*}{0.14} \\
\hline 1-7 times/week & $226(17.2 \%)$ & $1084(82.8 \%)$ & 1310 & & & \\
\hline$<1$ time/week or never & $58(14.2 \%)$ & $350(85.8 \%)$ & 408 & & & \\
\hline \multicolumn{4}{|l|}{ Ice creams } & \multirow{3}{*}{1.04} & \multirow{3}{*}{$0.79-1.36$} & \multirow{3}{*}{0.75} \\
\hline 1-7 times/week & $94(18.8 \%)$ & $408(81.2 \%)$ & 502 & & & \\
\hline$<1$ time/week or never & $220(18 \%)$ & $996(82 \%)$ & 1216 & & & \\
\hline \multicolumn{4}{|l|}{ Snacks } & \multirow{3}{*}{1.44} & \multirow{3}{*}{$1.03-2.03$} & \multirow{3}{*}{0.02} \\
\hline 1-7 times/week & $264(19.3 \%)$ & $1103(80.7 \%)$ & 1367 & & & \\
\hline$<1$ time/week or never & $50(14.2 \%)$ & $301(85.6 \%)$ & 351 & & & \\
\hline \multicolumn{4}{|l|}{ Vegetables } & \multirow{3}{*}{0.76} & \multirow{3}{*}{$0.52-1.12$} & \multirow{3}{*}{0.14} \\
\hline 1-7 times/week & $272(17.8 \%)$ & $1256(82.2 \%)$ & 1528 & & & \\
\hline$<1$ time/week or never & $42(22.1 \%)$ & $148(77.9 \%)$ & 190 & & & \\
\hline \multicolumn{4}{|l|}{ Fruits } & \multirow{3}{*}{1.00} & \multirow{3}{*}{$0.76-1.31$} & \multirow{3}{*}{0.97} \\
\hline 1-7 times/week & $221(18.3 \%)$ & $987(81.7 \%)$ & 1208 & & & \\
\hline$<1$ time/week or never & $93(18.2 \%)$ & $417(81.8 \%)$ & 510 & & & \\
\hline
\end{tabular}

\#Underweight and Normal weight; Note-Information regarding food frequency is taken for last one month and then categorized into 1-7 times/week and $<1$ time/week (means taken occasionally in a month) or never.

$84.6 \%$ of study subjects have the habit of taking food/snacks in between breakfast-lunch-supper and only $15.4 \%$ did not have this habit (Table 2). The prevalence of overweight/obesity is slightly high among those who have this habit $(18.4 \%)$ compared to those without this habit $(17.7 \%)$. This association is not statistically significant.

$31.7 \%$ of the study subjects do not take food from fast food centre and the proportion of study subjects who eat food from fast food centre 1-2 times. 3-4 times and $>4$ times is $49.4 \%, 10.9 \%$ and $8.0 \%$ respectively.
The prevalence of overweight and obesity is high among study subjects who eat food from fast food centre (21.8\%) compared to those who do not eat from fast food centre $(10.7 \%)$ which is statistically significant (Table 4).

Among the study subjects who give h/o taking food from fast food centre (1174), the prevalence of overweight/obesity is found to be high among those who take fast food for more than 2 times/week (40.8\%) compared to those who take 1-2 times/week. This is statistically significant (Table 5). 
The frequency of food intake of sweets, egg, meat, milk/curd, ice creams, snacks, vegetables and fruits was analyzed. There is significant association between consumption of sweets, egg, meat, and snacks and prevalence of overweight/obesity.

\section{DISCUSSION}

A number of studies suggest that sedentary behavior in children today is common and may be related to the development of overweight and obesity. ${ }^{14,15} \mathrm{~A}$ number of prospective studies on young children have confirmed that the decreased physical activity is associated with adipose weight gain over time .

It has been found in this study that sweets, egg, meat, and snacks are highly significant in increasing the prevalence of overweight/obesity. The prevalence is less among students taking vegetables 1-7 times/week. Similarly other studies also showed that dietary variety of sweets, snacks, condiments, entrees and carbohydrates is positively associated with body fatness whereas variety from vegetables is negatively associated. ${ }^{16,17}$ Non vegetarians have a higher prevalence of overweight/obesity (18.4\%) compared to vegetarians $(14.7 \%)$. The study subjects who eat food from fast food centre showed a risk of having overweight/obesity 2.33 times that of subjects who do not eat food from fast food centre and it is also observed that the prevalence of overweight /obesity is found to be high among those who take fast food for more than 2 times/week (40.8\%) compared to those who take 1-2 times/week. In the past 10 years in Kerala there has been a tremendous growth in the number of fast food joints and the frequency of children eating out has also gone up, coupled with the increased number of children with pocket money. All this has changed the diet to a high fat, high sugar low fibre diet and resulted in increase of prevalence. Similar diet patterns have shown high prevalence in various other studies too. ${ }^{16,17}$ There is no much difference in the prevalence between students having habit of taking snacks/food in-between meals and students without this habit. In a study carried out in UAE, obesity among students was associated with food intake between meals and in particular fast foods. ${ }^{18}$

\section{CONCLUSION}

The prevalence of overweight and obesity is high among study subjects who eat food from fast food centre $(21.8 \%)$ compared to those who do not eat from fast food centre $(10.7 \%)$.

There is significant association between consumption of sweets, egg, meat, and snacks and prevalence of overweight/obesity.
Funding: No funding sources Conflict of interest: None declared

Ethical approval: The study was approved by the Institutional Ethics Committee

\section{REFERENCES}

1. Martin SL, Lee SM, Lowry R. National prevalence and correlates of walking and bicycling to school. Am J Preventive Med. 2007;33(2):98-105.

2. Nguyen VT, Larson DE, Johnson RK, Goran MI. Fat intake and adiposity in children of lean and obese parents. Am J Clin Nutr. 1996;63:507-13.

3. Klesges RC, Stein RJ, Eck LH, Isbell TR, Klesges TM. Parental influence on food selection in young children and its relationships to childhood obesity. Am J Clin Nutr. 1991;53:859-64.

4. Molnar D and Livingstone B. Physical activity in relation to overweight and obesity in children and adolescents. Eur J Pedia. 2000;159(1):45-55.

5. Lightman SW, Pisarska K, Berman ER. Discrepancy between self-reported and actual caloric intake and exercise in obese subjects. $\mathrm{N}$ Engl J Med. 1992;327:1893-8.

6. Willett WC, Sampson L, Stampfer MJ, Rosner B, Bain C, Witschi J, Hennekens CH. Reproducibility and validity of food-frequency questionnaires. Am J Epidemiol. 1985;122(1):51-65.

7. Cook P, Rutishauser IHE, Seelig M. Comparable data on food and nutrient intake and physical measurements from the 1983, 1985 and 1995 National Nutrition Surveys. Commonwealth Department of Health and Aged Care, Canberra. 2001.

8. Marks GC, Webb K, Rutishauser IHE, Riley M. Monitoring food habits in the Australian population using short questions. Commonwealth Department of Health and Aged Care, Canberra.2001.

9. Carter RL, Sharbaugh CO, Stapell CA. Reliability and validity of the 24-hour recall. J Am Diet Assoc. 1981;79(5):542-7.

10. Buzzard M. 24-hour dietary recall and food record methods. Nutritional Epidemiology. W. Willett. New York, Oxford University Press. 1990:50-73.

11. Boeing H, Bohlscheid TS, Voss S, Schneeweiss S, Wahrendorf $\mathrm{J}$. The relative validity of vitamin intakes derived from a food frequency questionnaire compared to 24-hour recalls and biological measurements: results from the EPIC pilot study in Germany. Int J Epidemiology. 1997;26(1):82-90.

12. Rolland-Cachera MF, Bellisle F. No correlation between adiposity and food intake: why are working class children fatter? Am J Clin Nutr. 1986;44:77987.

13. Rolland C, Bellisle F, Pequignot F, Deheeger M, Sempe M. Influence of body fat distribution during childhood on body fat distribution in adulthood. Int J Obesity. 1990;14:473-81. 
14. Bärlocher A, Vetter W, Suter PM. Prevalence of overweight and obesity in Swiss adolescents. Praxis (Bern 1994). 2008;97(3):119-28.

15. Sallis JF, Prochaska JJ, Taylor WC. A review of correlates of physical activity of children and adolescents. Med Sci Sports Exerc. 2000;32(5):96375.

16. McCrory MA, Fuss PJ, Callum JE, Yao M, Vinken AG, Hays NP, Roberts SB. Dietary variety within food groups: association with energy intake and body fatness in men and women. Am J Clin Nutr. 1999;69(3):440-7.
17. Michael IG. Metabolic precursors and effects of obesity in children: a decade of progress, 19901999. Am J Clin Nutr. 2001;73(2):158-71.

18. Amine EK, Samy M. Obesity among female university students in the United Arab Emirates. JR Soc Health. 1996;116(2):91-6.

Cite this article as: Viswanatha $\mathrm{PG}$, Ramakrishna RN, Shanmugapariya D, Tejaswi HJ, Subathra V. Dietary pattern and obesity among children: descriptive study. Int J Community Med Public Health 2016;3:1399-403. 